\title{
Response to Letter on immunoassay measurement errors
}

\author{
Rolf H H Groenwold ${ }^{1,2}$ and Olaf M Dekkers (1) 1,3 \\ ${ }^{1}$ Department of Clinical Epidemiology, ${ }^{2}$ Department of Biomedical Data Sciences, and ${ }^{3}$ Department of Endocrinology, \\ Leiden University Medical Center, Leiden, the Netherlands
}

Correspondence should be addressed to $\mathrm{R} \mathrm{H} \mathrm{H}$ Groenwold Email

R.H.H.Groenwold@lumc.nl
We thank Gant Kanegusuku et al. for pointing out that laboratory measurements can be subject to measurement error too (1). We could not agree more. While our explanation focused on obvious examples of measurements that are too coarse (e.g. self-reported $\mathrm{BMI})$, we mentioned measurement error in laboratory measurements only briefly (e.g. cortisol levels) (2). But indeed, even measurements that may appear quite accurate (e.g. because these were made using cuttingedge technology) could in fact not reflect the true state of the phenomenon being quantified. It is this 'true state' of a variable that we refer to as 'error free', so for some variables, the error-free measurement may not even exist.

Irrespective of the type of measurement, key questions about the quality of the measurement are what is actually intended to be measured and how precise that measurement can ever be? The former equally applies for technical and non-technical measurements, while the latter often can be anticipated based on what is written on the instruction leaflet of the measurement device or what is published in the literature.

As an example, think of the measurement of body temperature, which could be measured for instance using an analogue armpit thermometer or a digital ear thermometer. Both measurements probably intend to measure the core body temperature. The armpit measurement is clearly not measured at the body core. In addition, the thermometer itself may be miscalibrated, but the analogue scale is prone to reading errors too. These aspects could result in some degree of measurement error. In contrast, when using a digital thermometer, reading of the temperature is (hopefully) not prone to reading errors, but nevertheless, the temperature is again not measured exactly at the body core and the device itself might be subject to some inaccuracy. The extent of the latter is commonly reported in the information leaflet of technical measurement devices for example as coefficient of variation (3). For other measurement devices this might be reported on, for instance in a scientific journal. This information helps in anticipating the possible impact of measurement error in studies in which the measurement device is used. This similarly applies to laboratory measurements. Often, however, this source of error is ignored, which may lead to researchers being overconfident about the validity and precision of their study results. We thank Gant Kanegusuku and colleagues for drawing attention to this relevant issue.

Declaration of interest

The authors declare that there is no conflict of interest that could be perceived as prejudicing the impartiality of this letter.

\section{Funding}

This research did not receive any specific grant from any funding agency in the public, commercial or not-for-profit sector.
(C) 2020 European Society of Endocrinology Printed in Great Britain
Published by Bioscientifica Ltd. 


\section{References}

1 Gant Kanegusuku A, Klubo-Gwiezdzinska J, Araque K \& Soldin SJ. Raising awareness of chronic measurement error intrinsic to immunoassay measurements of small molecule analytes. European Journal of Endocrinology 2020 184 L1-L2. (https://doi.org/10.1530/EJE20-1102)

2 Groenwold RHH \& Dekkers OM. Measurement error in clinical research, yes is matters. European Journal of Endocrinology 2020183 E3-E5. (https://doi.org/10.1530/EJE-20-0550)

3 Shechtman O. The coefficient of variation as an index of measurement reliability. In Methods of Clinical Epidemiology. Springer Series on Epidemiology and Public Health. Eds S Doi \& G Williams. Berlin, Heidelberg: Springer, 2013. (https://doi.org/10.1007/978-3-642-37131-8_4)

Received 14 October 2020

Revised version received 14 October 2020

Accepted 20 October 2020 